\title{
Sosialisasi Pemberian Infrared dan Tens pada Lansia di Desa Sukasari, Serdang Bedagai
}

\author{
Sulaiman ${ }^{1}$, Anggriani², Lagut Sutandra ${ }^{3}$ \\ 1,2, 3 STIKES Siti Hajar
}

\begin{tabular}{|c|c|}
\hline Article History & ABSTRACT \\
\hline \multirow[t]{2}{*}{$\begin{array}{l}\text { Received } 19.03 .2019 \\
\text { Received in revised form } \\
18.04 .2019 \\
\text { Accepted } 26.07 .2019 \\
\text { Available online } 20.08 .2019\end{array}$} & $\begin{array}{l}\text { DISSEMINATION OF GIVING INFRA-RED AND TENS TO THE ELDERLY IN } \\
\text { SUKASARI VILLAGE, SERDANG BEDAGAI. Elderly people are very susceptible } \\
\text { to health problems. These health problems are sometimes forgotten by the elderly } \\
\text { family to take them to the nearest Elderly integrated service post. Elderly in } \\
\text { Sukasari Village, Pegajahan Subdistrict, Serdang Bedagai Regency, which } \\
\text { attended } 72 \text { activities, the average elderly has physical problems and needs more } \\
\text { treatment by giving infrared and tens. In this service the method is carried out by } \\
\text { conducting counseling, training on the use of infra-red for the elderly, cadres and } \\
\text { families who follow community service. Giving infrared and tens rays greatly } \\
\text { gives a very significant impact in increasing the health status of the elderly in } \\
\text { Sukasari Village, Pegajahan District. }\end{array}$ \\
\hline & KEYWORDS: Elderly, Integrated service post, Infrared and Tens. \\
\hline
\end{tabular}

DOI: $10.30653 / 002.201942 .128$

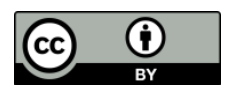

This is an open access article distributed under the terms of the Creative Commons Attribution 4.0 International License, which permits unrestricted use, distribution, and reproduction in any medium, provided the original work is properly cited. (c) 2019 Sulaiman, Anggriani, Lagut Sutandra.

\section{PENDAHULUAN}

Desa Sukasari merupakan salah satu desa yang ada di Kecamatan Pegajahan Kabupaten Serdang Berdagai Provinsi Sumatera Utara. Rata-rata penduduk bertani dan banyak masyarakat yang mengusahakan ubi kayu/singkong sebagai mata pencaharian dengan cara membuat beberapa produk olahan salah satunya adalah kerupuk opak sehingga desa ini dikenal sebagai sentra produksi olahan ubi kayu/singkong. Namun demikian banyak masyarakat yang lupa akan pentingnya kesehatan. Hal ini terjadi pada lanjut usia di desa tersebut mengalami gangguan-gangguan kesehatan, untuk itu perlu diberi dilakukan pengabdian dengan cara penanganan fisioterapi seperti pemberian sinar infrared dan Tens.

Infrared (IR) merupakan salah satu modalitas bagi seorang fisioterapis dalam menangani pasien fisioterapi yang mengalami berbagai gangguan fisik. Gangguan fisik

${ }^{1}$ Corresponding author: STIKES Siti Hajar, Jalan Jamin Ginting No.2, Medan Baru, Merdeka, Kec. Medan Baru, Kota Medan, Sumatera Utara 20222; Indonesia; Email: sulaiman@stikes-sitihajar.ac.id 
yang dialami oleh lanjut usia (lansia) sangatlah komplek, untuk itu diperlukan penanganan yang sangat serius. Pemberian sinar infrared (IR) diberikan kepada lansia dengan tujuan untuk menstimulasi reseptor panas yang berfungsi sebagai pengurang rasa nyeri, penguatan otot yang berperan penting dalam menjaga kesehatan lansia. Lansia sering terkena penyakit Osteoarthritis, obesitas, stoke, hipertensi, diabetes dan keseimbangan sehingga sangat mengganggu aktifitas fisik lansia dan keluarga. Pengabdian masyarakat yang dilakukan oleh (Sari, Sumarwati, \& Sutrisna, 2018) , bahwa pengetahuan kader dan lansia dalam mengelola hipertensi, tingkatkan pengetahuan dalam melakukan olahraga untuk mengurangi hipertensi, tingkatkan pengetahuan dalam manajemen diet, dan meningkatkan pengetahuan tentang pengobatan selft untuk mengurangi hipertensi. Ditingkatkan.

Selain IR, modalitas yang sangat mudah dan sederhana namun sangat bermanfaat yang diberikan kepada lansia adalah Transcutaneus Electrical Nerve Stimulation. (Tens). Tens merupakan suatu cara penggunaan energi listrik untuk merangsang saraf melalui permukaan kulit lebih dalam diandingkan IR. Selain manfaat diatas, tens juga dapat mengurangi rasa nyeri kronik yang terjadi pada lansia dan sangat efektif diberikan modalitas fisioterapi berupa tens (Santoso \& Fitriyani, 2013). Karena Adanya permasalahan yang muncul baik pada tingkat impainment, functional limitation, dan disability sehingga diperlukan penanganan fisioterapis secara efektif dalam hal ini adalah pemberian terapi dengan menggunakan Inf sinar infrared dan terapi latihan. Infrared. Untuk gangguan fisik berupa OA, stroke, keseimbangan tubuh dan lainnya diberikan penyinaran dengan dosis 3 kali seminggu dalam waktu 15, permasalahan yang didapatkan pasien lansia diatas 60 tahun sering terdiagnosis osteoarthritis. Setelah dilakukan terapi sebanyak 6 kali dengan modalitas Infrared, terjadi penurunan nyeri, peningkatan kekuatan otot, dan peningkatan kekuatan fungsional. Dalam proses pemulihan menujukan normal pada kasus OA membutuhkan waktu yang lama (Cahyo, 2017). Seiring dengan meningkatnya kesehatan lansia di Indonesia, proyeksi penduduk 2010-2035, Indonesia akan memasuki periode lansia (ageing), dimana 10\% penduduk akan berusia 60 tahun ke atas. Sejak tahun 2004 - 2015 memperlihatkan adanya peningkatan Usia Harapan Hidup di Indonesia dari 68,6 tahun menjadi 70,8 tahun dan proyeksi tahun 2030-2035 mencapai 72,2 tahun (Kemenkes RI, 2016)

Meningkatnya usia harapan hidup sebagai bukti gambaran keberhasilan kesehatan di Indonesia, namun disisi lain meningkatkanya usia harapan hidup menjadi beban pemerintah. Diperkirakan tahun 2017 jumlah penduduk lansia usia diatas 60 tahun sebanayak 23.658.21 jiwa (Kurniawan, 2017)

Dalam setiap kegiatan posyandu, sebagian besar lansia tidak memeriksa kesehatannya di posyandu dengan berbagai alasan. Hal ini yang menjadi permasalahan bagi lansia yang ada di Desa Sukasari sehingga kesehatan para lansia menurun. Hal ini dikarenakan keluarga lansia sibuk bekerja dan kegiatan di posyandu yang relative tidak banyak manfaat menurut lansia. Posyandu lansia merupakan salah satu upaya kesehatan dasar bersumber dari masyarakat yang melibatkan partisipasi masyarakat dalam pelaksanaannya. Posyandu juga sebagai perpanjangan tangan Puskesmas yang memberikan pelayanan dan pemantauan kesehatan yang dilaksanakan secara terpadu. Kegiatan dilaksanakan oleh kader kesehatan yang telah mendapatkan pendidikan dan pelatihan dari Puskesmas mengenai Pelayanan kesehatan dasar (Balitbang Kemenkes RI, 2010) 


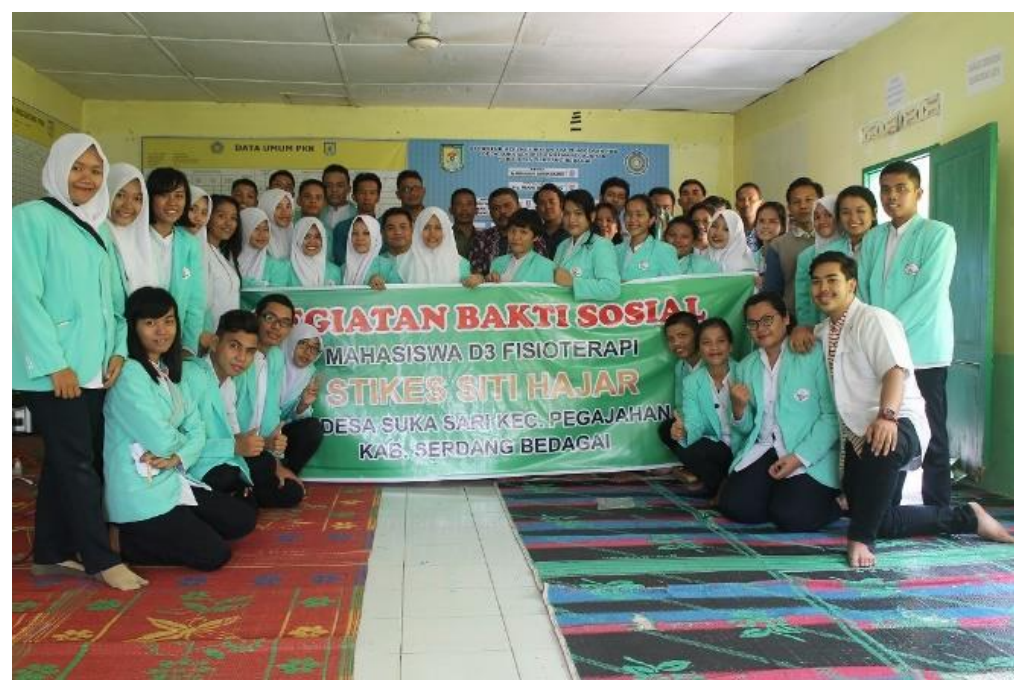

Gambar 1. Balai Desa Sukasari (tempat pelaksanaan pengabdian)

Pengabdian Kepada Masyarakat yang dilakukan oleh Sulaiman dkk terhadap kader posyandu lansia dalam pelatihan penggunaan infrared menunjukkan bahwa terjadi peningkatan kunjungan lansia ke posyandu lansia sebesar 30\% Kader posyandu dan keluarga lansia turut berpartisipasi aktif dalam membantu peningkatan kunjungan lansia ke posyandu lansia (Sulaiman, Sutandra, \& Vera, 2018). Begitu juga pengabdian yang dilakukan di Desa Suka Raya Kecamatan Pancurbatu Kabupaten Serdang Bedagai Sumatera Utara. Banyak sekali lansia mengalami gangguan musculokeletal yang di alami oleh lansia seperti gangguan keseimbangan postur tubuh yang bururk terhadap lansia. Hal ini terjadi salah satu penyebabnya karena lansia malas datang ke posyandu setiap bulannya untuk mengecek kesehatan lansia (Sulaiman \& Anggriani, 2018).

Selain itu lansia yang malas memeriksa kesehatannya bisa terkena Diabetes Melitus (DM) dimana merupakan keadaan yang seringkali dikaitkan dengan meningkatnya risiko kesakitan dan kematian. Lanjut usia (lansia) yang menderita DM seringkali juga mengalami penyakit lainnya, ketidakmampuan fisik, gangguan psikososial dan fungsi kognisi, serta meningkatnya pelayanan kedokteran. Padaakhirnya, komplikasi yang terjadi akan mempengaruhi kualitas hidup lansia. Lansia pria mempunyai rata-rata skor lebih tinggi pada domain kesehatan fisik dan hubungan sosial dibandingkan dengan lansia wanita. (Khairani, 2016).

Berdasarkan analisis situasi diperoleh permasalahan yang dihadapi oleh lansia di Desa Sukasari Kecamatan Pegajahan adalah sebagai berikut: 1) Lanjut usia rata-rata mengalami gangguan musculoskeletal yaitu Osteoarthritis, lowbackpain, stroke, pernafasan, nyeri diabetes dan keseimbangan postur tubuh; 2) Kegiatan posyandu lansia yang dilaksanakan khusus lansia sangat sedikti diminati;3) transportasi yang tidak ada ke temapt posyandu. Tiga hal tersebut melatarbelakangi kegiatan pengabdian masyarakat dilakukan di Desa Sukasari Kecamatan Pegajahan Kabupaten Serdang Bedagai dilakukan.

Melihat kompleksnya permasalahan yang di hadapi oleh lansia di Desa Sukasari Kecamatan Pegajahan, tim pengabdian melakukan permasalahan yang prioritas terlebih dahulu, yaitu memberikan pemberian sinar infrared kepada lansia yang mengalami gangguan fisik seperti osteoarthritis, lowbackpain, stroke, keseimbangan postur tubuh dan gangguan fisik lainnya. 
Berdasarkan permasalahan prioritas di atas, tim pengabdian melakukan langkahlangkah yang tepat dan solutif untuk dapat menyelesaikan permasalahan prioritas yang dihadapi oleh para lansia sebagai berikut: 1) Memberikan Penyuluhan kesehatan; 2) Memberikan pelatihan pada kader posyandu; 3) Memberian penyinaran sinar infrared dan pemberian tens kepada lansia. Langkah-langkah tersebut memberikan target dalam kegiatan pengabdian ini secara umum, yaitu terjadi perubahan sosial masyarakat dalam memandang pentingnya kesehatan. Lansia dan keluarga rajin datang ke posyandu untuk memeriksa kesehatannya.

\section{METODE PELAKSANAAN}

Pengabdian masyarakat yang dilakukan ini agar sesuai target yang akan diharapkan dan dengan melihat skala prioritas solusi yang telah ditetapkan, maka metode pelaksanaannya adalah sebagai berikut:

\section{Memberikan Penyuluhan}

Kegiatan penyuluhan dilakukan di Balai Desa Sukasari dihadiri oleh lansia dan keluarga lansia. Dalam penyuluhan ini tim memberikan ceramah bagaimana agar kesehatan lansia tetap terjaga sampai akhir hayat. Memberikan semangat hidup kepada lansia. Lansia merasa dirinya tidak berguna dihadapan para keluarga, masyarakat, merasa menjadi beban, sehingga dapat mengakibatkan menurunnya kesehatan lansia. Dalam penyuluhan ini tim juga memberikan penerangan teknik dan manfaat infrared bagi lansia dan keluarga. Selain harga infrared yang realtif murah, manfaat infrared juga sangat banyak. Keluarga lansia nantinya dapat memberikan kepada lansia karena telah mengikuti penyuluhan yang diberikan oleh tim pengabdian. Penyuluhan dan pelatihan dilakukan mulai pukul 09.00 - dengan 14.00 WIB. Hal ini dilakukan penyuluhan terlebih dahulu agar kegiatan dihari kedua para lansia dan keluarga telah memahami manfaat pemberian sinar infrared dan tens. Selain itu penyuluhan ini juga memberikan bantuan kepada kader berupa alat infrared kepada kader. Tujuannya agar pada saat kegiatan posyandu setiap bulannya dapat infrared dapat dipergunakan dengan baik. Penyuluhan ini juga memberikan sesi tanya jawab kepada seluruh peserta.

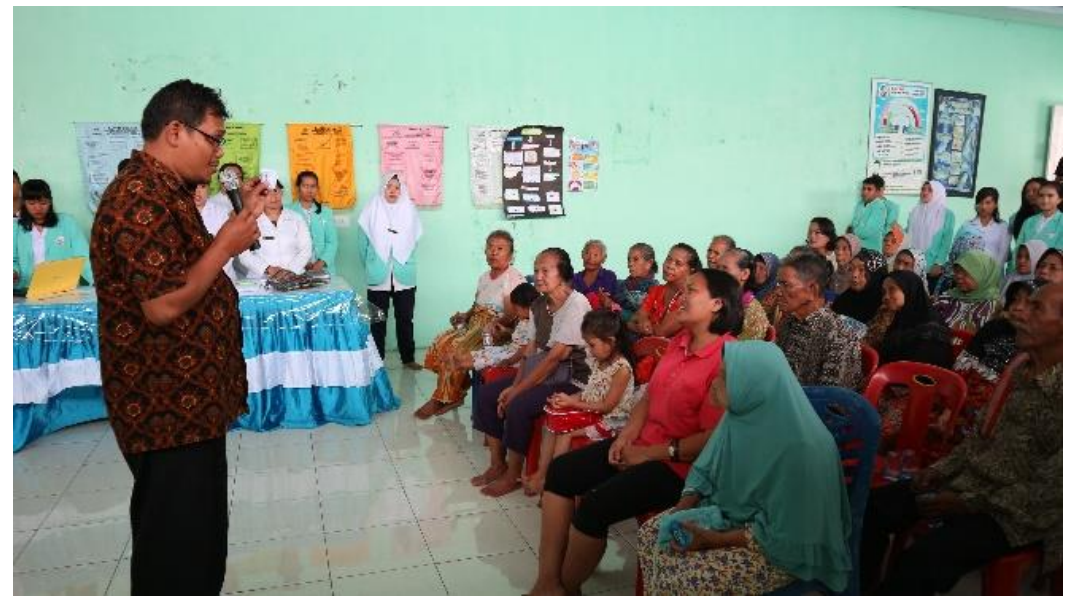

Gambar 2. Penyuluhan dan Tanya Jawab 


\section{Memberikan Senam Lansia}

Senam lansia ini sangat penting diberikan pada setiap kegiatan, kegiatan senam lansia ini dipandu oleh mahasiswa Fisioterapi Siti Hajar yang ikut berperan serta dalam pengabdian masyarakat. Senam lansia ini diberikan agar lansia dilakukan selama kegiatan pengabdian. Hal ini bertujuan agar seluruh anggota tubunya dapat segar kembali setelah melakukan kegiatan senam lansia dan dapat mengikuti kegaitan pengabdian kepada masyarakat ini sampai dengan selesai.

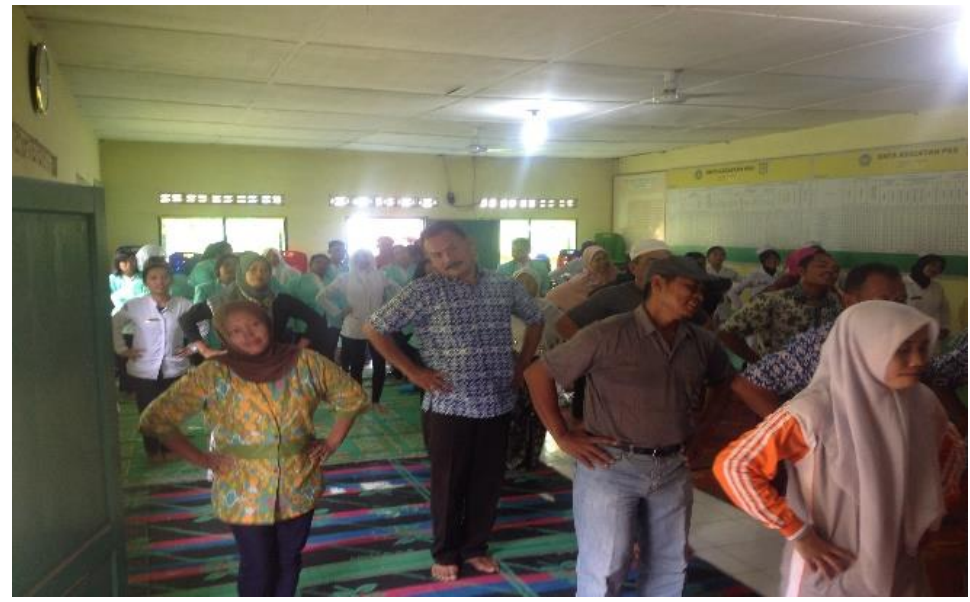

Gambar 3. Senam lansia di Balai Desa Sukasari

\section{Pemberian Sinar Infrared dan Tens}

Setelah melakukan sosialisasi dengan cara memberikan ceramah pada lansia dan keluarga serta kader serta senam lansia yang diikuti oleh lansia dan para kader posyandu lansia. Tahap selanjutnya melakukan Tanya jawab dengan lansia dan keluarga. Hal ini dilakukan unutk menegtahui sampai sejauh mana informasi yang disampaikan dapat diterima dengan baik Pada hari kedua pengabdian adalah penanganan langsung dengan cara memberikan sinar infrared dan tens kepada lansia. Lansia sangat antusias untuk mendapatkan penanganan oleh tim pengabdian. Pemberian sinar infrared ini dilakukan selama 15 menit pertama kemudian dilakukan lagi 15 menit berikutnya. Dengan diberikan infrared ini sirkulasi darah dalam tubuh lansia akan lancar. Sehingga gangguan-gangguan kesehatan yang dihadapai lansia dapat berkurang.

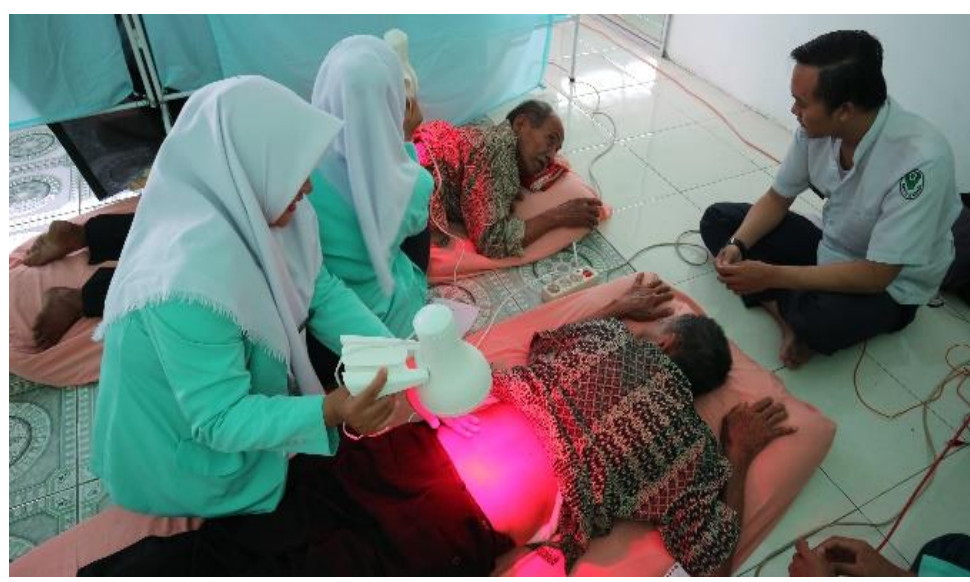

Gambar 4. Pemberian Sinar Infrared 


\section{HASIL DAN PEMBAHASAN}

Dalam pelaksanaan pengabdian ini melibatkan mahasiswa fisioterapi yang akan menyelesaikan pendidikannya. Peserta diikuti oleh seluruh masyarakat Desa Sukasari kecamatan Pegajahan yang keluarganya terdapat lansia dan membutuhkan penanganan fisioterapi.

Tabel 1. Peserta Kegiatan Pengabdian Masyarakat

\begin{tabular}{lcc}
\hline Karakteristik & Frekuensi (f) & Persentase (\%) \\
\hline Umur & & \\
60-74 tahun (Elderly) & 56 & 77,8 \\
$>$ 75 tahun (Old) & 16 & 22,2 \\
Jenis Kelamin & & \\
Laki-laki & 41 & 56,9 \\
Perempuan & 31 & 43,1 \\
Pendidikan & & \\
SD & 13 & 18,1 \\
SMP & 34 & 47,2 \\
SMA & 24 & 33,3 \\
Perguruan Tinggi & 1 & 1,4 \\
Pekerjaan & & \\
Petani & 49 & 68,1 \\
Wiraswasta & 17 & 23,6 \\
Pensiunan & 6 & 8,3 \\
Suku & & \\
Karo & 14 & 19,4 \\
Jawa & 46 & 63,9 \\
Batak & 6 & 8,3 \\
Minang & 3 & 4,2 \\
Aceh & 2 & 2,8 \\
Nias & 1 & 1,4 \\
\hline
\end{tabular}

Dari hasil pelaksanaan perserta pengabdian rata-rata masyarakat merespon dengan baik kegiatan yang dilakukan, Kemudian lansia meminta agar kegiatan pengabdian ini bisa dilakukan setiap bulannya. Hasil respon peserta pengabdian ini dapat dilihata pada Tabel 2 Berikut ini.

Tabel 2 Respon Peserta Pengabdian

\begin{tabular}{lll}
\hline Kategori & Frekuensi & Persentase \\
\hline Baik & 60 & 83,3 \\
\hline Tidak Baik & 12 & 16.7 \\
\hline Jumlah & 72 & 100 \\
\hline
\end{tabular}

Selain itu dalam pengabdian ini tim dalam melaksanakan tugas menghasilkan dan menemukan beberapa hal sebagai berikut 
1) Peningkatan derajat kesehatan lansia di Desa Sukasari Kecamatan Pegajahan setelah dilakukan penyuluhan dan pemberian penyinaran sinar infrared

2) Gangguan kesehatan berupa OA,LBP, stoke, keseimbangan tubuh berkurang karena telah diberikan penyinaran sinar infrared.

3) Lansia, keluarga dan kader menjadi paham akan manfaat sinar infrared dan teknik penggunaan alat infrared tersebut.

Hasil pengabdian ini sesuai yang dilaksanakan di Desa Suka Raya bahwa ada pengaruh peningkatan pengetahuan kader, lansia dan keluarga tentang kesehatan setelah diberikan penyuluhan dan pemberian sinar infrared (Sulaiman, Sutandra, Vera, \& Anggriani, 2018). Begitu juga penelitian yang dilakukan di Desa Suka Raya menyatakan bahwa pengetahuan lansia, sikap lansia, dukungan keluarga, dukungan kader dan keterjangkauan responden berhubungan dengan pemanfaatan Posyandu lansia, sehingga variabel tersebut sangat mempengaruhi derajat kesehatan lansia.

\section{SIMPULAN}

Dari hasil dari tim pengabdian yang dilakukan selama 2 hari, ting pengabdian dapat menyimpulan sebagai berikut. 1) Pemberian sinar infrared dan tens dapat diberikan dalam kegiatan posyandu lansia di Desa Sukasari Kecamatan Pegajahan Kabupaten Serdang Bedagai sangat bermanfaat bagi lansia; 2) Target pengabdian tercapai sesuai harapan yang telah ditetapkan diawal pengabdian.

Selanjutnya, perlu dilakukan pengabdian setiap bulannya di Desa Sukasari Kecamatan Pegajahan, dengan metode yang lainnya dan durasi waktuyang lebih lama lagi.

\section{UCAPAN TERIMA KASIH}

Dalam melakukan Pengabdian Kepada Masyarakat tim pengabdian mengucapkan banyak terimakasih kepada Lembaga Pengabdian pada Masyarakat Stikes Siti Hajar Medan, atas bantuan dana dan kepercayaan yang di berikan kepada tim pengabdian ini, sehingga tim pengabdian dapat melaksanakan dengan baik, sesuai target dan dapat memberikan solusi dengan baik kepada masyarakat Desa Sukasari Kecamatan Pegajahan. Kepercayaan ini semoga dapat diberikan kembali ditahun yang akan datang.

\section{REFERENSI}

Cahyo, Is. (2017). Penatalaksanaan fisioterapi pada kasus osteoarthritis genu sinistra di RSU Aisyiyah Ponorogo. Libraryums, 1(1), 1-9.

Kemenkes RI. (2016). Situasi lanjut usia (lansia). Jakarta: Kemenkes RI.

Khairani, R. (2016). Prevalensi diabetes mellitus dan hubungannya dengan kualitas hidup lanjut usia di masyarakat. Universa Medicina, 26(1), 18-26.

Kurniawan, R. (Ed.) (2017). Profil kesehatan Indonesia 2017. Jakarta: Kemenkes RI. 
Balitbang Kemenkes RI (2010). Riset Kesehatan dasar (Riskesdas) 2010. Jakarta: Badan Penelitian dan Pengembangan Kesehatan Kementerian Kesehatan RI.

Santoso, T. B., \& Fitriyani, W. (2013). Efektifitas dan kenyamanan transcutaneus electrical nerve stimulation (TENS) pulse burst dan arus trabert dalam mengurangi nyeri kronik di lutut pada usia lanjut. Surakarta: UMS.

Sari, Y., Sumarwati, M., \& Sutrisna, E. (2018). Pemberdayaan kader Posyandu Lansia untuk pencegahan hipertensi dan komplikasinya di Purwokerto. Jurnal Pengabdian Pada Masyarakat, 3(1), 27-34. doi: 10.30653/002.201831.49

Sulaiman, \& Anggriani, A. (2018). Efek postur tubuh terhadap keseimbangan lanjut usia di Desa Suka Raya Kecamatan Pancur Batu. JUMANTIK (Jurnal Ilmiah Penelitian Kesehatan), 3(2), 127-140.

Sulaiman, Sutandra, L., Vera, Y., \& Anggriani, A. (2018). Pendampingan kader Posyandu lansia di Suka Raya. Journal of Dedicators Community, 2(2), 116-122. 